\title{
Bone Lineage Proteins in the Entheses of the Midfoot in Patients with Spondyloarthritis
}

\author{
César Pacheco-Tena, Ruy Pérez-Tamayo, Carlos Pineda, Susana A. González-Chávez, \\ Celia Quiñonez-Flores, Antonio Ugalde Vitelly, Robert D. Inman, Jane E. Aubin, \\ Janitzia Vázquez-Mellado, and Rubén Burgos-Vargas
}

ABSTRACT. Objective. Patients with juvenile-onset spondyloarthritis (SpA) may develop ankylosis of the midfoot resembling the spinal changes seen in patients with ankylosing spondylitis (AS). The study of the histopathology of the feet of patients with tarsitis could help us understand the pathogenesis of bone formation in affected structures in the SpA. The objective of our study was to describe the histopathologic characteristics of the midfoot in patients with tarsitis associated with SpA.

Methods. We obtained synovial sheaths, entheses, and bone samples from 20 patients with SpA with midfoot pain/tenderness and swelling. Tissue samples underwent H\&E staining; immunohistochemistry for CD3, CD4, CD8, CD68, and CD20 cell identification; and immunofluorescence for bone lineage proteins, including osteocalcin, osteopontin, parathyroid hormone-related protein, bone sialoprotein, and alkaline phosphatase.

Results. Slight edema and hyalinization were found in some tendon sheaths, and few inflammatory cells were detected in the entheses. In bones, we found some changes suggesting osteoproliferation, including endochondral and intramembranous ossification, but no inflammatory cells. In entheses showing bone proliferation, we detected osteocalcin and osteopontin in cells with a fibroblastmesenchymal phenotype, suggesting the induction of entheseal cells toward an osteoblast phenotype.

Conclusion. Osteoproliferation and abnormal expression of bone lineage proteins, but no inflammatory infiltration, characterize midfoot involvement in patients with SpA. In this sense, tarsitis (or ankylosing tarsitis) resembles the involvement of the spine in patients with AS. Ossification may be in part explained by the differentiation of mesenchymal entheseal cells toward the osteoblastic lineage. (First Release Dec 15 2014; J Rheumatol 2015;42:630-7; doi:10.3899/jrheum.140218)

Key Indexing Terms: ANKYLOSING SPONDYLITIS ANKYLOSING TARSITIS OSTEOPONTIN

\footnotetext{
From the Facultad de Medicina, Universidad Autónoma de Chihuahua, Chihuahua; Unidad de Medicina Experimental, Facultad de Medicina, Universidad Nacional Autónoma de México; Instituto Nacional de Rehabilitación; Servicio de Cirugía Plástica y Reconstructiva, and Servicio de Reumatología, Hospital General de México, México D.F., México; Arthritis Centre for Excellence, Toronto Western Hospital, and Department of Molecular Genetics University of Toronto, Toronto, Ontario, Canada.

C. Pacheco-Tena, MD; S.A. González-Chávez, MSc; C. Quiñonez-Flores, MSc, Facultad de Medicina, Universidad Autónoma de Chihuahua; R. Pérez-Tamayo, MD, Unidad de Medicina Experimental, Facultad de Medicina, Universidad Nacional Autónoma de México; C. Pineda, MD, Dirección de Investigación, Instituto Nacional de Rehabilitación;

A. Ugalde Vitelly, MD, Servicio de Cirugía Plástica y Reconstructiva, Hospital General de México; J. Vázquez-Mellado, PhD;

R. Burgos-Vargas, MD, Servicio de Reumatología, Hospital General de México, Facultad de Medicina, Universidad Nacional Autónoma de México; R.D. Inman, MD, Arthritis Centre for Excellence, Toronto Western Hospital; J.E. Aubin, PhD, Department of Molecular Genetics, University of Toronto.

Address correspondence to Dr. R. Burgos-Vargas, Rheumatology Department, Hospital General de México, Dr. Balmis 148, México DF 06720,México.E-mail:r.burgos.vargas@gmail.com

Accepted for publication October 10, 2014.
}

Spondyloarthritis (SpA) refers to a group of HLA-B27-positive rheumatic diseases that share clinical and genetic features ${ }^{1}$. Signs, symptoms, and radiographic features define the diseases and conditions that constitute the group. Inflammation of the synovium and enthesis, as well as ossification of the latter, are the pathologic processes that stand behind the clinical picture of SpA, mainly ankylosing spondylitis (AS).

In Latin American patients with SpA, the prevalence of peripheral arthritis and enthesitis is higher and occurs earlier than in whites ${ }^{2}$. A unique form of severe involvement of the feet, named ankylosing tarsitis (AT), has been described in Mexican youngsters with $\mathrm{SpA}^{3,4}$. AT consists of tarsal swelling, synovial inflammation, bone overgrowth, endochondral ossification, enthesophytosis, bone bridging, and ankylosis of the tarsal bones (Figure 1). The changes that occur in this form of disease resemble those found in the radiographic and magnetic resonance imaging (MRI) studies of the spine in patients with AS. 


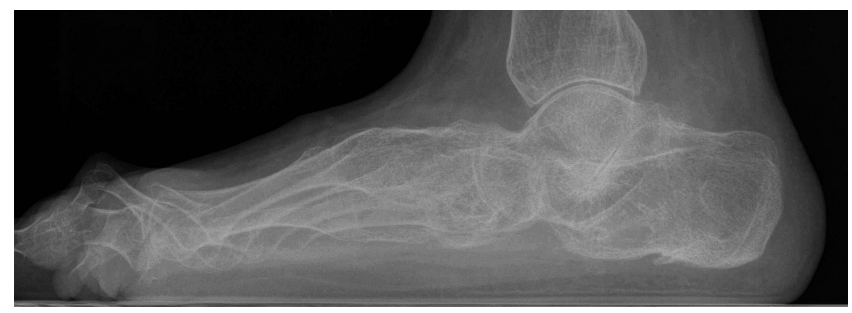

Figure 1. Radiograph from a 31-year-old patient with endstage AT. Complete fusion of the tarsal joints as a result of widespread bone proliferation. The disease onset was at 17 years and inflammatory back pain started at 21 years. The patient fulfilled AS criteria at age 25. AT: ankylosing tarsitis; AS: ankylosing spondylitis.

The scarcity of histopathologic samples, particularly of the spine and sacroiliac (SI) joints, has hampered our understanding of the pathogenesis of SpA, especially in patients with early disease at the start of the ossification. We assume that the study of the midfoot bones of patients with SpA undergoing ossification could be a complementary approach.

Both inflammation and osteoproliferation are fundamental processes to be understood.

Histopathologic studies of the spine and SI joints of patients with AS have focused primarily on inflammation; these studies have assessed the immune cell populations and also their secreted cytokines. $\mathrm{T}$ cells are the predominant cell found in the infiltrates (mainly the CD4, CD8, CD45RO, and CD45RA subtypes), but macrophages are also present at lower counts ${ }^{5,6,7}$; inflammatory infiltrates are mainly located in the bone marrow. Proinflammatory cytokines, such as tumor necrosis factor (TNF)- $\alpha$, have been detected in areas of inflammatory infiltration whereas the transforming growth factor (TGF)- $\beta$ is expressed in areas of new bone formation. Local bone marrow macrophages and dendritic cells produce interleukin (IL)- $23^{8}$ and Th cells 17 produce IL- $17^{9}$.

Ossification, on the other hand, has not been studied extensively in patients with SpA despite its relevance in a patient's prognosis and its potential as a therapeutic target. Ossification of entheseal and spinal structures in SpA involves either the endochondral or the intramembranous pathways ${ }^{10,11}$. This ossification may result either from the proliferative response of the periosteal edges intruding into the enthesis, or from the differentiation of mesenchymal cell precursors in the neighboring tissues after an osteogenic stimulus. The intimate mechanisms behind this ossification are likely diverse to induce ossification in a diversity of cell lineages that reside in different anatomical structures (i.e., nonentheseal zygapophyseal cartilage vs entheseal intradiscal annulus fibrosus). For a tissue to become ossified, the cell precursors require osteogenic stimuli; then the primed cells undergo sequential stages of differentiation in which they express an array of stage-specific protein markers. Among those markers, some define the early stages of differ- entiation like bone sialoprotein (BSP) while the expression of others such as osteopontin (OPN) or osteocalcin (OCN) define latter stages, including mature osteocytes ${ }^{12,13}$.

The expression of these markers for bone lineage commitment has not been studied in tissues undergoing ossification of the SpA. Understanding the process and the mediators for the abnormal ossification in SpA tissues could provide an additional rationale to design specific therapy against osteoproliferation.

We analyzed the histological picture of the osteoproliferation response in the midfoot bones from patients with AT, with particular interest in the expression of bone lineage commitment proteins within the ossifying tissues.

\section{MATERIALS AND METHODS}

Ours is a cross-sectional study of adult patients with undifferentiated $\mathrm{SpA}^{14}$ and $\mathrm{AS}^{15}$ with active inflammation of the tarsal region (defined as the midfoot, from the ankle to the metatarsophalangeal joints) as defined by the presence of swelling or limitation of motion accompanied by heat, pain, or tenderness for $>2$ weeks. Patients with a history of congenital malformations or acquired disease, or trauma, surgical, or immobilization procedures at any time were not included in our study. Patients who had received local foot and/or intramuscular injections and/or oral glucocorticoids in the last 3 months were not included in our study. The Hospital General de Mexico review board for human research approved our study protocol. Our study was conducted according to the Declaration of Helsinki and local guidelines. All patients signed a consent form after being informed about the nature of the study, in particular the procedures and risks of the foot biopsy.

Clinical evaluation. Demographic and clinical data were obtained for all patients. The patients included in our study underwent the following assessments: the number of painful and swollen joints, enthesis and tarsal area counts for tenderness and swelling, Schober test, occiput-to-wall distance, and chest expansion. In addition, patients completed the Bath Ankylosing Spondylitis Disease Activity Index (BASDAI) ${ }^{16}$, the Bath Ankylosing Spondylitis Functional Index ${ }^{17}$, and the Bath Ankylosing Spondylitis Patient Global Score ${ }^{18}$ questionnaires. We also measured C-reactive protein (CRP) serum levels or the erythrocyte sedimentation rate. Radiographic studies included those of the feet as well as the SI joints; their scoring relied on the SpA-Tarsal Radiographic Index (SpA-TRI ${ }^{19}$ and the modified New York AS criteria for the SI joints.

Site selection and biopsy procedures. Biopsy sites were selected by 2 of the investigators (CP-T and AU-V). We obtained tissue samples from tendon attachments at the dorsal aspect of the tarsus, specifically the talonavicular ligament, as well as the flexor tendons synovial sheaths of the toes, including those from extensor digitorum longus and brevis, extensor hallucis longus, the inferior extensor retinaculum, and the peroneus longus and brevis. Criteria for site selection included easy access to structures displaying at least 1 of the following characteristics: (1) spontaneous pain, (2) pain and/or tenderness elicited by digital palpation, and (3) soft tissue swelling.

Tissue samples were obtained under local, subcutaneous anesthesia (lidocaine $1 \%$ and epinephrine $0.005 \%$ ) in a circular pattern around the biopsy site. Tissue samples were obtained either by open skin dissection with a scalpel or percutaneous soft tissue and bone biopsy using a Craig needle instrument set and under fluoroscopic guidance. We obtained fragments of tendon and its synovial sheath, enthesis-ligament or tendon attachments, bone, and whenever possible, bone marrow samples. Our initial strategy targeted the tendon sheaths insertion along the tarsal bones, but based on the preliminary histologic review, after the third patient we decided to include an additional bone biopsy; therefore, our analysis included 20 tendon sheaths and 18 bone biopsies.

Personal non-commercial use only. The Journal of Rheumatology Copyright @ $\subset$ 2015. All rights reserved 
Tissues were fixed in $4 \%$ paraformaldehyde. Bone samples were dipped and decalcified in nitric acid until suitable for sectioning. Once decalcified, all tissue samples were washed in ethanol, dehydrated in xylol, and embedded in paraffin. After sectioning, the samples were mounted on several slides for H\&E staining. A pathologist (RP-T), blinded to demographic and clinical characteristics, evaluated all samples and determined the presence or absence of inflammatory infiltrates, edema, fibrosis, hyalinization, vascularization, synovitis, and bony proliferation. The pathological features of the cartilage, periosteum, and bone marrow were also described.

Immunohistochemistry of the inflammatory infiltrates was performed with specific monoclonal antibodies (DAKO) against CD3, CD4, CD8 CD20, and CD68 markers and the following protocol: after standard microwave antigen retrieval (citrate buffer at $\mathrm{pH} 6.0$ for $6 \mathrm{~min}$ ), the slides were blocked with $10 \%$ goat serum, incubated overnight at $4^{\circ} \mathrm{C}$ with the primary antibody [1:200 dilution in phosphate buffered saline (PBS)], washed in PBS, and then incubated with biotinylated secondary antibody (specie-complementary to the primary; 1:1000 dilution in PBS) for $1 \mathrm{~h}$ at room temperature. Sections were then incubated with Avidin-BiotinComplex/horseradish peroxidase complex for $30 \mathrm{~min}$, washed with PBS, and then treated with 3,3' diamonibenzidine (Sigma D-5637) and 0.17\% hydrogen peroxide in Tris buffer; counterstaining was done with hematoxylin. Immunohistochemistry for bone markers OPN, OCN, and parathyroid hormone-related protein (PTHrP) was also performed.

Immunofluorescence was performed with monoclonal antibodies (Santa Cruz Biotechnology) against the following markers of the osteoblast lineage cells ${ }^{12,20}$ : OPN, OCN, PTHrP, and BSP. Following blocking with $10 \%$ goat serum in PBS, sections were incubated with primary antibody (1:200 dilution) in a humid chamber at $4^{\circ} \mathrm{C}$ overnight, washed in PBS, and then incubated at room temperature in the dark for $1 \mathrm{~h}$ with the isotype-specific secondary antibody in a 1:1000 dilution: fluorescein isothiocyanate to OPN and OCN, Texas red to PTHrP, and cyanine 5-labeled to PTHrP. Fibroblast Marker (ER-TR7; Santa Cruz Biotechnology) was used to perform colocalizations with OPN and OCN, and a colocalization of OCN and OPN was carried out. Labeling was evaluated by epifluorescence microscopy (Zeiss Axioscope) and/or laser scanning confocal microscopy (LSM 700 Axio Observer, Carl Zeiss), and then analyzed with the Axiovision and/or Zen10 program. The same observer carried out immunofluorescence evaluation and interpretation, and the slides were photographed under conditions optimized by the software for the exposure times.

\section{RESULTS}

We included 20 patients, mostly males, with juvenile $(\mathrm{n}=$ $11)$ or adult $(\mathrm{n}=9)$ onset $\mathrm{AS}^{15}(\mathrm{n}=13)$ or undifferentiated $\mathrm{SpA}(\mathrm{n}=7)$. Their mean age $\pm \mathrm{SD}$ at the time of our study was $27.15 \pm 8.9$ years. Most patients complained of axial symptoms in combination with tarsal swelling and pain. At least $50 \%$ of the group had severe proliferative changes in the tarsus according to SpA-TRI (Supplementary Figure 1, available online at jrheum.org). The mean swollen joint counts and enthesitis sites were $3.2 \pm 2.75$ and $8.6 \pm 5.4$, respectively. Twelve patients were in functional class III or IV. No patient had been previously or currently treated with biologic agents. The patients were divided based on the presence or absence of bone proliferative changes. In the group with proliferation, certain tendencies were observed: they were younger at the time of the biopsy and at disease onset, had higher swollen and tender joint and enthesitis counts, and with higher BASDAI scores, the latter was the only variable achieving statistical significance (Table 1).

Histopathology. Most tissue samples corresponded to the peroneal and tibial tendons' sheaths, and in some cases, the
Table 1. Comparison of patient groups defined by the presence or absence of proliferation in bone biopsies. Values are mean \pm SD unless otherwise specified.

\begin{tabular}{lccc}
\hline Patients, $\mathrm{n}=18$ & $\begin{array}{c}\text { Patients with } \\
\text { No Proliferation, } \\
\mathrm{n}=9\end{array}$ & $\begin{array}{c}\text { Patients with } \\
\text { Proliferation, } \\
\mathrm{n}=9\end{array}$ & $\mathrm{p}$ \\
\hline Sex, M/F & $7 / 2$ & $6 / 3$ & 0.45 \\
Age, yrs & $30.78 \pm 8.27$ & $23.78 \pm 2.68$ & 0.08 \\
Age at onset, yrs & $24.78 \pm 8.85$ & $19.78 \pm 8.30$ & 0.23 \\
Adult/juvenile-onset & $5 / 4$ & $3 / 6$ & 0.63 \\
Disease duration, yrs & $4.30 \pm 1.43$ & $2.39 \pm 0.79$ & 0.24 \\
Swollen joint count, 0-66 & $2.56 \pm 2.02$ & $3.67 \pm 2.95$ & 0.37 \\
Enthesitis index & $7.78 \pm 4.96$ & $10.78 \pm 5.44$ & 0.24 \\
SpA-TRI, $\leq 2$ / $\geq 3$ & $6 / 3$ & $3 / 6$ & 0.17 \\
BASDAI & $3.66 \pm 1.43$ & $6.20 \pm 1.21$ & $\mathbf{0 . 0 0 4}$ \\
BASFI & $3.94 \pm 3.18$ & $6.54 \pm 2.79$ & 0.155 \\
BAS-G & $1.77 \pm 0.85$ & $2.5 \pm 0.87$ & 0.141 \\
\hline
\end{tabular}

Significant data are in bold face. SpA-TRI: Spondyloarthritis-Tarsal Radiographic Index; BASDAI: Bath Ankylosing Spondylitis Disease Activity Index; BASFI: Bath Ankylosing Spondylitis Functional Index; BAS-G: Bath Ankylosing Spondylitis Patient Global Score.

dorsal aspect of the navicular bone or the naviculocuneiform joint. In these sheaths, slight inflammation accompanied by some interfibrillar edema and disorganization (Figure 2A) and loosening of collagen fibers (Figure 2B) was evident (Table 2). Some cases showed dilated vascular loops with some signs of vascular proliferation and redundancy (Figure 2C). In cases showing evidence of chronicity, there was more often sparse cellularity, a relative absence of fibroblasts, and the development of compacted tendon sheaths; this aspect was different from that found in the extracellular matrix, which showed collagen fiber hyalinization (Figure 2D). In one-third of the cases, we obtained synovial tissues that showed mild inflammatory processes consisting of a slight leukocyte infiltrate (Figure 2E) with no synovial cell proliferation.

Some samples showed marked vascularity (Figure 2F) and intrusion of osteoid material within the cartilage matrix (Figure 2G), evolving in a pattern that looked similar to that of the trabecular bone, suggesting endochondral ossification.

Entheses of the tibiofibular muscles in the dorsal aspects of the navicular, cuboid, and cuneiform bones showed some irregularities at the interface of the fibrous attachment to the periosteum (Figure 2H) and some indications of cortical bone proliferation and entheseal ossification (Figure 2I), sometimes away from the cortical bone (Figure 2J, 2K, 2L).

In several sections, we observed recent osteoid deposits extending directly into the enthesis. The appearance of the cortical bone aspect suggested bone apposition. Interestingly, we found no significant leukocyte infiltration in the bone marrow.

Detection of cell subpopulations by immunohistochemistry. Scarce mononuclear cell inflammatory infiltrates, mainly perivascular, were found in tendon sheaths and within the 

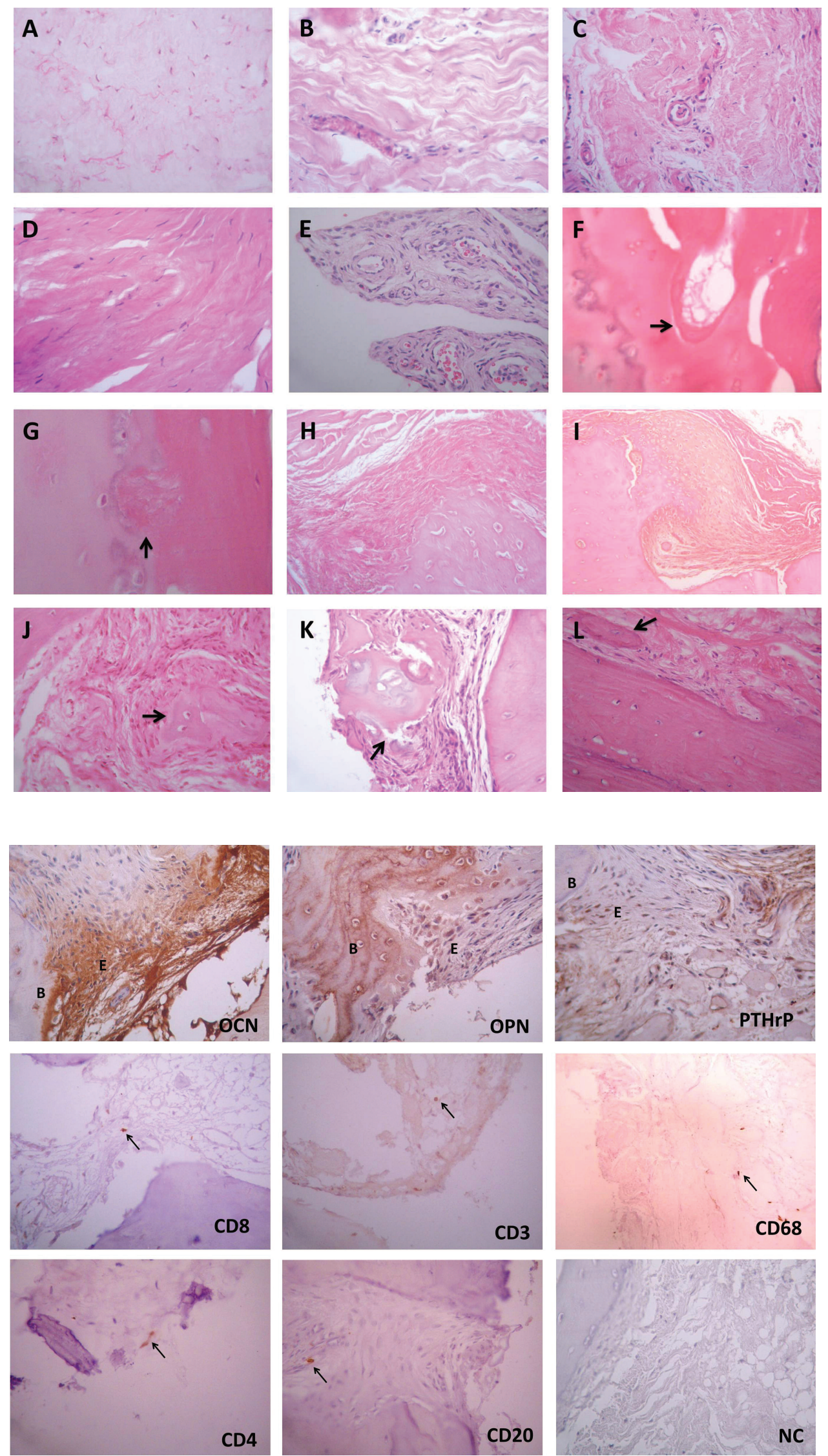

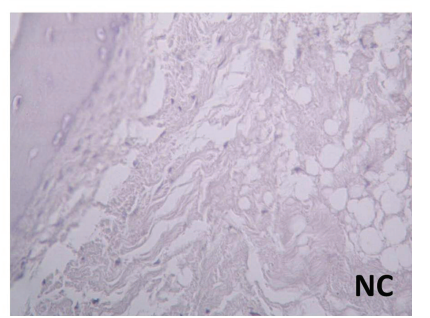

Figure 2. Histologic images of several structures in the joints and entheses of patients with AT. Tendon sheaths presented edema with disorganization of the collagen fibers $(\mathrm{A}, \mathrm{B}, \mathrm{C})$ and vascular proliferation $(\mathrm{B}, \mathrm{C})$. In cases with more chronic inflammation, the collagen fibers showed hyalinization (D). Synovial membrane (E) also showed high vascularity, but no significant inflammatory infiltrates. Subchondral bone (F, G) showed irregular borders with bone proliferative response and tendency to intrude in the cartilage matrix (arrows). The entheses showed blurred bone-tendon borders, disorganized fibrillar structure, and the proliferation of tenocytes and periosteal cells $(\mathrm{H}, \mathrm{I})$. Evident ossification of the entheseal tissue beyond the periosteum (J, K, L; black arrows) was detected, suggesting a transformation of the entheseal cells toward osteoblastic lineage. No significant inflammation was detected adjacent to the tissue undergoing ossification. AT: ankylosing tarsitis.

Figure 3. Immunohistochemistry photographs of entheseal biopsies in patients with AT. Bone lineage proteins $(\mathrm{OCN}, \mathrm{OPN}$, $\mathrm{PTHrP}$ ) are expressed in both the bone (B) and in the entheses (E) with different patterns, with OCN by far the most abundant. Cellular subpopulation detection (CD3, CD4, CD8, CD20, CD68) showed a very isolated staining, suggesting a minimal presence of immune cells. A negative control $(\mathrm{NC})$ is presented as a reference. AT: ankylosing tarsitis; OCN: osteocalcin; OPN: osteopontin; PTHrP: parathyroid hormone-related protein. 
Table 2. Findings in tendon sheaths biopsies and bony tissues.

\begin{tabular}{llc}
\hline Structure & Findings & $\mathrm{n}(\%)$ \\
\hline Tendon sheaths, $\mathrm{n}=20$ & Edema & $7(35)$ \\
& Vascular proliferation & $9(45)$ \\
& Fiber hyalinization & $7(35)$ \\
& Synovial lining cells & $7(35)$ \\
Bone, $\mathrm{n}=18$ & Inflammation & $4(20)$ \\
& Proliferation & $9(50)$ \\
& Inflammation & $8(44.4)$ \\
& Combined inflammation & $4(22.2)$ \\
& proliferation & $6(33.3)$ \\
& Bone marrow observed & $15(83.3)$ \\
& Vascular proliferation & $7(38.9)$ \\
\hline
\end{tabular}

entheses. In all cases, the number of cells was very low to be counted (Figure 3): positive detection of isolated CD3+ cells was possible in $16 \%$ of the slides, CD4 was detected in $36 \%, \mathrm{CD} 8$ in $20 \%, \mathrm{CD} 20$ in 40\%, and CD68 in 29\% (Figure $3)$.

This pattern of distribution replicates the findings of Benjamin, et $a l$, in which inflammatory cells were found infiltrating the tendon or entheses, but rather were associated with perivascular structures ${ }^{10}$.
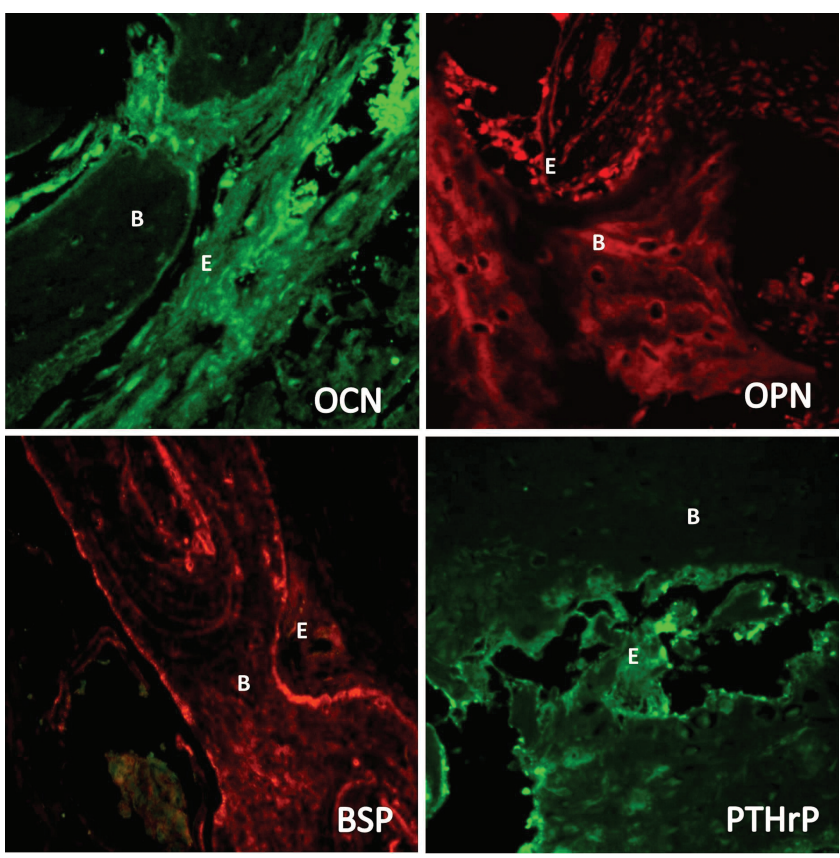

Figure 4. Immunofluorescence detection of bone lineage proteins in the bone (B) and the enthesis (E) of patients with AT. OCN is detected on osteocytes and in the enthesis even in the extracellular matrix, but not in the bone matrix. OPN is detected in the bone matrix and within cells in the entheses. BSP is mostly expressed in the bone matrix. PTHrP is basically absent from the bone matrix and osteocytes, and is strongly expressed in the periosteum and in the entheseal tissue. AT: ankylosing tarsitis; OCN: osteocalcin; OPN: osteopontin; BSP: bone sialoprotein; PTHrP: parathyroid hormone-related protein.
Immunofluorescence studies. OCN, OPN, BSP, and PTHrP were found in the entheseal and osteal tissues of 9 patients showing bone proliferation (Figure 4). OCN is a marker of mature postproliferative cells; the labeling was strong and evident in the bone matrix, osteocytes, and osteoblasts, but particularly intense in the entheses $(77 \%)$ and periosteal tissues (Supplementary Figures 2 and 3, available online at jrheum.org). OPN, which is a marker for osteoblast differentiation at early and later stages, was evident in the bone matrix, in the osteoblasts, and expressed in the entheses $(55 \%)$. BSP staining was prominent in the bone matrix, osteoblasts, and osteocytes, but was inconsistently found in
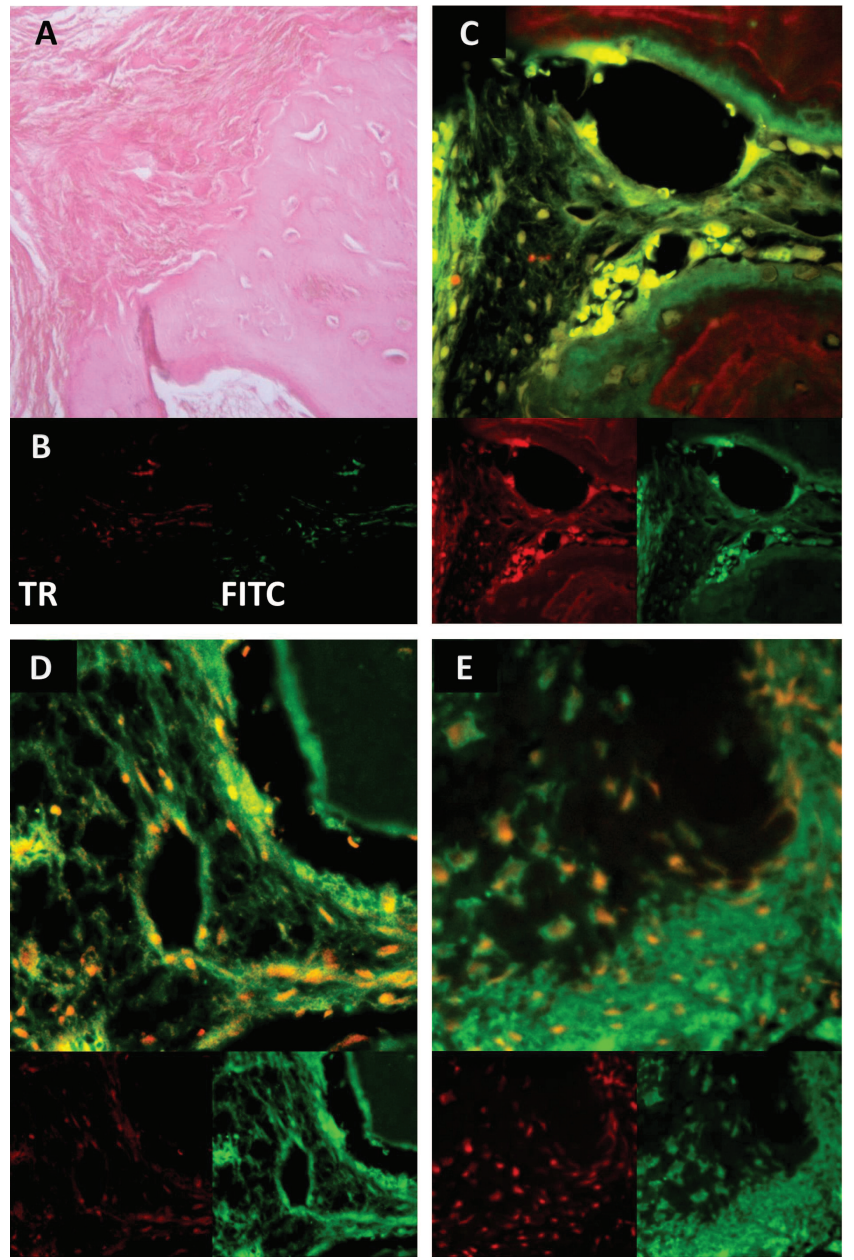

Figure 5. Expression of OCN and OPN by entheseal fibroblast. A. H\&E reference micrograph (40x) of an enthesis. B. Confocal micrographs of negative control staining sampling both wavelengths. C. Colocalization confocal micrographs of OPN (red) and OCN (green) in the enthesis showing a stronger expression of OPN in the bone matrix and of OCN in the periosteal bone; both colocalize in the entheseal cells confirming their link to bone lineage. D. Colocalization confocal micrographs of OCN (green) and fibroblast marker (red) confirming the expression of OCN by entheseal fibroblasts. E. Colocalization confocal micrographs of OPN (green) and fibroblast marker (red) showing the expression of OPN by entheseal fibroblasts. OCN: osteocalcin; OPN: osteopontin. 
the entheses $(22 \%)$. PTHrP expression was absent from the bone matrix, and seen primarily in the osteoblasts and occasionally in the entheses $(11 \%)$, although with a milder intensity than $\mathrm{OCN}$.

We detected colocalization of OPN and OCN in several biopsies and there was a coexpression in entheseal cells, although both proteins were expressed in different regions in the bone, with OCN more abundant in the periosteal and entheseal region (Figure 5C). Finally, both OCN and OPN colocalized with a fibroblast marker in the enthesis (Figure $5 \mathrm{D}$ and $5 \mathrm{E}$, respectively). The production of both bone lineage proteins by fibroblasts within the enthesis proves their differentiation toward osteoid precursors.

\section{DISCUSSION}

Our study analyzed the histopathological findings of the entheses and joints of the midfoot of patients with active SpA and characterized immune cell subpopulations osteoblastic lineage cells in the tissues. The rationale for selecting the feet for our study is based on the similarities found in the radiographic and MRI studies of patients with axial SpA, particularly AS, and patients with peripheral arthritis and enthesitis, specifically AT. The involvement of the foot in patients with $\mathrm{SpA}$, particularly of those with juvenile-onset SpA, may evolve from active inflammatory stages to partial or complete joint space narrowing and bony bridging between the tarsal bones. These changes resemble those found in the SI joints of patients with AS, including subchondral bone fusion and enthesophyte formation as consequences of intramembranous ossification of the entheses.

Interestingly, we found only scarce mononuclear cell inflammatory infiltration, and mainly CD20+ and CD4+ cell subtypes, in the synovium of tendon sheaths and in the vascular structures adjacent to the entheses. CD4 rather than CD8 $\mathrm{T}$ cell subtypes predominated in a previous study of the SI joints, which also found TNF- $\alpha$ and TGF- $\beta$ in inflammatory and bone areas of the SI joints, respectively ${ }^{21}$. Francois, et $a l^{7}$ and Appel, et $a l^{5}$ found CD3+ T cells, and less frequently CD8+ cells, in bone marrow inflammatory infiltrates of patients with both early and longstanding AS.

Higher cell counts in the bone marrow infiltrates have been correlated with MRI findings ${ }^{6}$; patients with a higher activity score in MRI also exhibit higher inflammatory cell counts in SI joint biopsies.

We did not find any significant accumulation of inflammatory cells in the bone marrow of the tarsal bones. This finding could be explained by the fact that the bones where bone edema and inflammation are detectable by MRI are the large ones (calcaneus and astragalus) and the signal is weaker in cuneiforms and navicular. Nevertheless, the latter do indeed exhibit bone bridging and ankylosis. While most animal models of SpA develop important mononuclear cell infiltration, including in the tarsal region before ossification of the enthesis becomes clear ${ }^{22}$, enthesophytosis and bone ankylosis develop in the absence of bone marrow inflammation in the ankylosing enthesopathy murine model of SpA.

One of the most interesting findings in our study suggests the possibility of intramembranous ossification of the enthesis and subchondral osteoproliferation, with the entheseal cells expressing osteoblast-associated proteins in patients with bone proliferative changes in the absence of extensive inflammation. Both OPN and OCN were expressed in cells with fibroblastic (mesenchymal) phenotype in the fibrous entheses, whereas a more restricted-to-the-bone distribution was observed for both BSP and PTHrP. It is worth noting that OPN is expressed in a variety of cell types and participates in remodeling of normal tissues and tumorigenesis ${ }^{23}$. It is, however, also a marker of the osteoblasts in normal and pathological calcification processes, including atherosclerosis $24,25,26,27$. OCN is a noncollagenous vitamin $\mathrm{K}$-dependent protein expressed and secreted in the late stage of osteoblast differentiation ${ }^{13}$. While some evidence supports a role for OCN in bone mineral maturation, considerable effort is going toward determining its precise role in carboxylated or noncarboxylated forms in bone and other tissues ${ }^{28}$. Although OCN is not constitutively expressed on normal tendons, it is upregulated in tendons undergoing abnormal ossification $25,29,30,31$. Interestingly, the identification of $\mathrm{OCN}$ in the fibrous entheses of the tarsal joints in our study suggests a role for this protein in AT. The absence of a direct comparator limits our interpretation significantly. However, we have clinical and imaging evidence of abnormal ossification of the tarsal joints in these patients, and some molecular mechanisms should account for it. OCN is expressed in tissues undergoing abnormal ossification; it was in the entheses of our patients. It must be mentioned, however, that only half of the patients with AT had proliferation-suggestive lesions, and half had inflammatory infiltrates.

Indeed, this link between inflammation and bone formation remains an unresolved issue in SpA. Inflammation and tissue damage constitute the initial insults, whereas healing and repairing are the subsequent processes that bring about, by independent mechanisms such as mechanical factors, the reengineering of the bone. MRI studies have shown some evidence that inflammation (defined as bone edema) at the vertebral corner precedes syndesmophyte formation in anti-TNF-naive and anti-TNF-treated patients even though the effect of anti-TNF agents impedes the progression of the disease $^{32,33,34}$. In addition, it seems that the prognosis of healed lesions differs from those showing fat infiltration, but the risk for syndesmophyte formation is about the same. Radiographic progression has been associated with high CRP levels, BASDAI, and bone inflammation on $\mathrm{MRI}^{35}$.

The study of animal models documents the relationship Personal non-commercial use only. The Journal of Rheumatology Copyright @ 2015 . All rights reserved. 
between inflammation and bone proliferation markers. Collagen I and III, BSP, and OCN upregulation has been described in the proteoglycan-induced spondylitis murine mode $^{36}$. Additionally, Lories, et al demonstrated a potential role for the bone morphogenetic proteins in the entheseal ossification and also a theoretical connection with mechanosensing proteins of the family Wingless Int $(\mathrm{Wnt})^{37}$. Aberrant Wnt signaling was also observed in the spontaneous ankylosis seen in ank/ank mice, which like the tissues in our present study, reveals little inflammation at site of ankylosis ${ }^{38}$.

The decalcifying process interfered with mRNA and cytokine transcript identification. However, the scarcity of inflammation in our samples did not warrant any significant cytokine identification. In contrast, we identified bone lineage proteins in our tissue samples. We found no correlation between clinical findings on examination and histopathologic findings. Bone, tendon, and entheses tenderness did not correlate with histologic findings in many cases.

We report an osteoproliferation process in patients with severe involvement of the tarsal joints and entheses in patients with AT associated with SpA. Our findings suggest the differentiation of entheseal cells toward an osteoblastic lineage and the formation of bone islets embedded within the enthesis matrix. The scarcity of inflammation infiltration suggests that osteoproliferation in the tarsal region might result from a predominantly mechanical rather than an inflammatory phenomenon. Because most patients developing AT have juvenile-onset disease, it is possible that bone growth factors might also play a role in this form of SpA.

\section{ONLINE SUPPLEMENT}

Supplementary data for this article are available online at jrheum.org.

\section{REFERENCES}

1. Moll JM, Haslock I, Wright V. Seronegative spondarthritides. In: Scott JT, Copeman WSC, eds. Copeman's textbook of the rheumatic diseases. 5th ed. Edinburgh: Churchill Livingstone; 1978:578-91

2. Casasola-Vargas JC, Castro Villegas MC, Morote G, Huerta Sil G, Muñoz Gomariz E, et al. A cross-sectional comparative study of Mexican and Spanish patients with spondyloarthropathies. Ann Rheum Dis 2004;63 Suppl 1:1111.

3. Burgos-Vargas R, Naranjo A, Castillo J, Katona G. Ankylosing spondylitis in the Mexican mestizo: patterns of disease according to age at onset. J Rheumatol 1989;16:186-91.

4. Burgos-Vargas R, Granados Arriola J. Ankylosing spondylitis and related diseases in the Mexican mestizo. In: Khan MA, ed. Seronegative spondyloarthropathies. Spine: state of the art reviews. Philadelphia: Hanley \& Belfus; 1990:4;665-78.

5. Appel H, Loddenkemper C, Grozdanovic Z, Ebhardt H, Dreimann $\mathrm{M}$, Hempfing A, et al. Correlation of histopathological findings and magnetic resonance imaging in the spine of patients with ankylosing spondylitis. Arthritis Res Ther 2006;8:R143.

6. Bollow M, Fischer T, Reisshauer H, Backhaus M, Sieper J, Hamm B, et al. Quantitative analyses of sacroiliac biopsies in spondyloarthropathies: $\mathrm{T}$ cells and macrophages predominate in early and active sacroiliitis- cellularity correlates with the degree of enhancement detected by magnetic resonance imaging. Ann Rheum Dis 2000;59:135-40.

7. François RJ, Neure L, Sieper J, Braun J. Immunohistological examination of open sacroiliac biopsies of patients with ankylosing spondylitis: detection of tumour necrosis factor alpha in two patients with early disease and transforming growth factor beta in three more advanced cases. Ann Rheum Dis 2006;65:713-20.

8. Appel H, Maier R, Bleil J, Hempfing A, Loddenkemper C, Schlichting $\mathrm{U}$, et al. In situ analysis of interleukin-23- and interleukin-12-positive cells in the spine of patients with ankylosing spondylitis. Arthritis Rheum 2013;65:1522-9.

9. Appel H, Maier R, Wu P, Scheer R, Hempfing A, Kayser R, et al. Analysis of IL-17(+) cells in facet joints of patients with spondyloarthritis suggests that the innate immune pathway might be of greater relevance than the Th17-mediated adaptive immune response. Arthritis Res Ther 2011;13:R95.

10. Benjamin M, Toumi H, Suzuki D, Hayashi K, McGonagle D. Evidence for a distinctive pattern of bone formation in enthesophytes. Ann Rheum Dis 2009;68:1003-10.

11. Appel H, Maier R, Loddenkemper C, Kayser R, Meier O, Hempfing A, et al. Immunohistochemical analysis of osteoblasts in zygapophyseal joints of patients with ankylosing spondylitis reveal repair mechanisms similar to osteoarthritis. J Rheumatol 2010;37:823-8

12. Aubin JE. Advances in the osteoblast lineage. Biochem Cell Biol 1998;76:899-910.

13. Liu F, Malaval L, Aubin JE. The mature osteoblast phenotype is characterized by extensive plasticity. Exp Cell Res 1997; 232:97-105.

14. Dougados M, van der Linden S, Juhlin R, Huitfeldt B, Amor B, Calin A, et al. The European Spondylarthropathy Study Group preliminary criteria for the classification of spondylarthropathy. Arthritis Rheum 1991;34:1218-27.

15. van der Linden S, Valkenburg HA, Cats A. Evaluation of diagnostic criteria for ankylosing spondylitis. A proposal for modification of the New York criteria. Arthritis Rheum 1984;27:361-8.

16. Garrett S, Jenkinson T, Kennedy LG, Whitelock H, Gaisford P, Calin A. A new approach to defining disease status in ankylosing spondylitis: the Bath Ankylosing Spondylitis Disease Activity Index. J Rheumatol 1994;21:2286-91.

17. Calin A, Garrett S, Whitelock H, Kennedy LG, O'Hea J, Mallorie $\mathrm{P}$, et al. A new approach to defining functional ability in ankylosing spondylitis: the development of the Bath Ankylosing Spondylitis Functional Index. J Rheumatol 1994;21:2281-5.

18. Jones SD, Steiner A, Garrett SL, Calin A. The Bath Ankylosing Spondylitis Patient Global Score (BAS-G). Br J Rheumatol 1996;35:66-71

19. Pacheco-Tena C, Londoño JD, Cazarín-Barrientos J, Martínez A, Vázquez-Mellado J, Moctezuma JF, et al. Development of a radiographic index to assess the tarsal involvement in patients with spondyloarthropathies. Ann Rheum Dis 2002;61:330-4.

20. Aubin JE, Turksen K. Monoclonal antibodies as tools for studying the osteoblast lineage. Microsc Res Tech 1996;33:128-40.

21. Braun J, Bollow M, Neure L, Seipelt E, Seyrekbasan F, Herbst H, et al. Use of immunohistologic and in situ hybridization techniques in the examination of sacroiliac joint biopsy specimens from patients with ankylosing spondylitis. Arthritis Rheum 1995; 38:499-505.

22. van Duivenvoorde LM, Dorris ML, Satumtira N, van Tok MN, Redlich K, Tak PP, et al. Relationship between inflammation, bone destruction, and osteoproliferation in the HLA-B27/human $\beta 2$-microglobulin-transgenic rat model of spondylarthritis. Arthritis Rheum 2012;64:3210-9

23. Denhardt DT, Guo X. Osteopontin: a protein with diverse functions.

Personal non-commercial use only. The Journal of Rheumatology Copyright @ 2015. All rights reserved. 
FASEB J 1993;7:1475-82.

24. Oliva F, Barisani D, Grasso A, Maffulli N. Gene expression analysis in calcific tendinopathy of the rotator cuff. Eur Cell Mater 2011;21:548-57

25. Kim SY, Choi HY, Myung KB, Choi YW. The expression of molecular mediators in the idiopathic cutaneous calcification and ossification. J Cutan Pathol 2008;35:826-31.

26. Vattikuti R, Towler DA. Osteogenic regulation of vascular calcification: an early perspective. Am J Physiol Endocrinol Metab 2004;286:E686-96

27. Mori N, Majima T, Iwasaki N, Kon S, Miyakawa K, Kimura C, et al. The role of osteopontin in tendon tissue remodeling after denervation-induced mechanical stress deprivation. Matrix Biol 2007;26:42-53.

28. Gundberg CM, Lian JB, Booth SL. Vitamin K-dependent carboxylation of osteocalcin: friend or foe? Adv Nutr 2012; 3:149-57.

29. Rui YF, Lui PPY, Rolf CG, Wong YM, Lee YW, Chan KM. Expression of chondro-osteogenic BMPs in clinical samples of patellar tendinopathy. Knee Surg Sports Traumatol Arthrosc 2012;20:1409-17.

30. Pauly S, Klatte F, Strobel C, Schmidmaier G, Greiner S, Scheibel M, et al. BMP-2 and BMP-7 affect human rotator cuff tendon cells in vitro. J Shoulder Elb Surg 2012;21:464-73.

31. Manjila S, Miller E, Awadallah A, Murakami S, Cohen ML, Cohen AR. Ossified choroid plexus papilloma of the fourth ventricle: elucidation of the mechanism of osteogenesis in benign brain tumors. J Neurosurg Pediatr 2013;12:13-20.
32. Baraliakos X, Listing J, Rudwaleit M, Sieper J, Braun J. The relationship between inflammation and new bone formation in patients with ankylosing spondylitis. Arthritis Res Ther 2008;10:R104.

33. Maksymowych WP, Chiowchanwisawakit P, Clare T, Pedersen SJ, Østergaard M, Lambert RG. Inflammatory lesions of the spine on magnetic resonance imaging predict the development of new syndesmophytes in ankylosing spondylitis: evidence of a relationship between inflammation and new bone formation. Arthritis Rheum 2009;60:93-102.

34. Haroon N, Inman RD, Learch TJ, Weisman MH, Lee M, Rahbar $\mathrm{MH}$, et al. The impact of tumor necrosis factor $\alpha$ inhibitors on radiographic progression in ankylosing spondylitis. Arthritis Rheum 2013;65:2645-54

35. Kiltz U, Baraliakos X, Karakostas P, Igelmann M, Kalthoff L, Klink C, et al. Do patients with non-radiographic axial spondylarthritis differ from patients with ankylosing spondylitis? Arthritis Care Res 2012;64:1415-22.

36. Haynes KR, Pettit AR, Duan R, Tseng HW, Glant TT, Brown MA, et al. Excessive bone formation in a mouse model of ankylosing spondylitis is associated with decreases in Wnt pathway inhibitors. Arthritis Res Ther 2012;14:R253.

37. Lories RJ, Derese I, Luyten FP. Modulation of bone morphogenetic protein signaling inhibits the onset and progression of ankylosing enthesitis. J Clin Invest 2005;115:1571-9.

38. Las Heras F, Pritzker KP, So A, Tsui HW, Chiu B, Inman RD, et al. Aberrant chondrocyte hypertrophy and activation of $\beta$-catenin signaling precede joint ankylosis in ank/ank mice. J Rheumatol 2012;39:583-93. 